\title{
Expert System Approach for CAD/CAM Integration \& Optimization based on International Standard (STEP) and Computer based Concurrent Engineering
}

\author{
${ }^{* 1}$ Morteza Sadegh Amalnik, ${ }^{2}$ M.K. Moayyedi, ${ }^{3}$ M.Mirzaei \\ ${ }^{* 1}$ Faculity of Engineering, University of Qom, Qom,I.R. Iran and Director of Environment Research Center \\ ${ }^{2}$ Assist. Prof. and director of education \& research in faculity of engineering of Qom University \\ ${ }^{3}$ Assist. Prof.of mechanical engineering department of Qom University.
}

\section{ABSTRACT}

This paper addresses the concept of the Expert system approach for CASD/CAM integration and optimization of product design and manufacturing in computer base concurrent engineering environment. The Expert system links with design and manufacturing databases. The design specification is acquired through a feature based approach. The Expert system links with material, tools, CNC machine center data and databases. For each design feature, the expert system provides information needed for design and manufacturing optimization. The expert system can be used as an advisory system for designers and manufacturing engineers using STEP (standard for exchange of product data) AP224 standard. and also for new CNC machine center operators. A designer uses proengineers software and feature base library and design a part. Design data stored in data base according to international standard STEP format. All suppliers can used the latest design data through computer network system and STEP design data. The result of table 1 shows that the expert system estimates correctly machining cycle time and cost and penetration rate. In practical, estimation of machining time and cost, feeds and all other parameters are difficult to obtain. In contrast the expert system can provide this estimation usually in less than 20 seconds.

\section{Keywords}

Expert system, STEP, Manufacturing time, cost

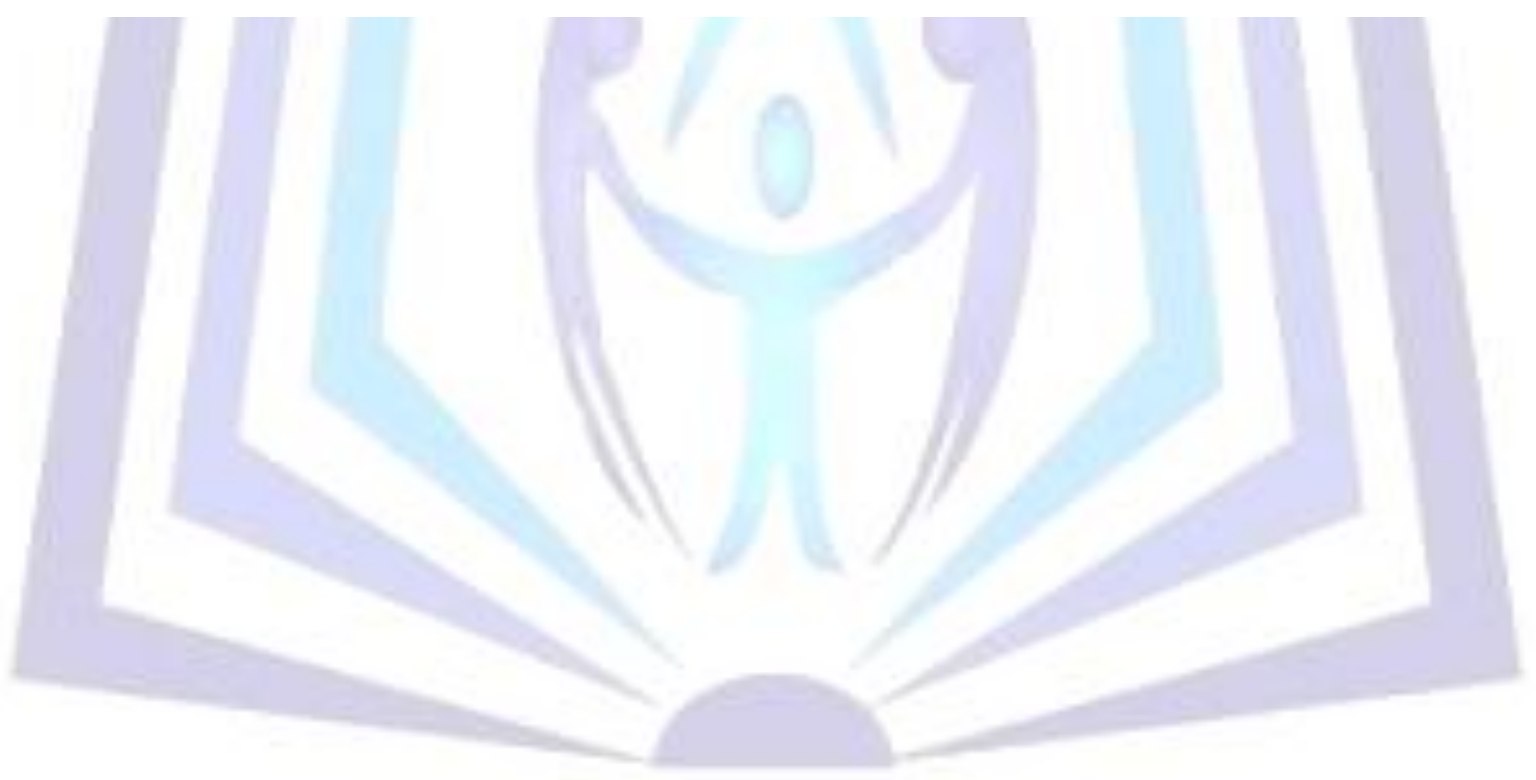

\section{Council for Innovative Research}

Peer Review Research Publishing System

Journal: INTERNATIONAL JOURNAL OF COMPUTERS \& TECHNOLOGY

Vol 14 . No. 5

www.ijctonline.com, editorijctonline@gmail.com 


\section{INTRODUCTION}

To be competitive in the market, industries must deal with the world-wide challenges in producing high-quality goods at low costs. In the 21st century, there is no place for traditional product development. Most of product development time and cost related to the early stage of design. Design decisions are taken in the early design stages. More often designers have little knowledge of the manufacturing difficulties. Therefore, designers typically designs components without consideration of manufacturing time, cost, and manufacturing difficulties. However, research in computer-aided design and manufacturing (CAD/CAM) has been aimed at providing computer support for the later design stages. Automated calculation and analysis of manufacturing cycle time and cost and manufacturability during the conceptual design stage has become the focus of the research community. Over the past few decades, to accommodate these increasing global challenges, manufacturers have made a significant progress toward quality and productivity improvement. This progress can be reflected in today's market by the increasing quality levels and decreasing prices of merchandises, especially for high-tech and mechanical products. These advancements have brought in exciting and interesting reforms in quality design and philosophy, one of which is the application of robust design [1-4]. Much research has been devoted to the theory of design Extensive comparison of the various systematic modern design methods can be found in literature. Product design begins with a need and ends with detailed drawings and all the accompanying information necessary for manufacturing the product. Product design is a complex and iterative process; and most studies have divided the design process into two, three or four stages. The classic design model has four stages, i.e design specification, conceptual design, preliminary design, (also called embodiment design or fundamental design in some studies), and detailed design The transition of design from one stage to another is a gradual process and the design evolves from one stage to another rather than an abrupt jump from one stage to the next. Especially in the context of providing computer support for design process, it is difficult to separate these design stages individually. With the aim of developing a computer system to support the product design during all the stages. A common characteristic of early design stage is that the design options are still being explored and compared. design data in these stages is incomplete and abstract. The detailed design stage is more about refining the design selected in the early design stages. As proposed by Taguchi, the objective of robust design is to make a product or process least sensitive to manufacturing variations, deterioration over time and environmental conditions [5-7]. It is a cost-effective way to improve quality, because it builds quality into products and processes through design, simultaneously with little impact on machining cycle time and cost. Philosophically, robust design consists of three basic steps; (1) System Design, (2) Parameter Design, and (3) Tolerance Design [8-9]. The objective of System Design is to obtain a workable prototype model of the product. The parameters of parts as well as components, except general dimensions of products, are not determined in this step. Much of the previous and current effort in industries is concentrated on this step. In addition to the development of a workable model, in this step, we also select materials, subsystems or parts based on general strength requirements, functional requirements and economical effects. The environmental factors or considerations for material selection and life cycle analysis can be integrated into this step. Parameter Design, which is the most important and effective step in Robust Design, focuses on parameter setting selection for design factors. In this step, engineers intend to design a robust product by selecting the optimal parameter settings of the design factors. The goal of robustness is achieved by selecting the best parameter levels rather than using expensive parts or components. The design can be optimize by using optimum parameters through expert system in concurrent engineering environment.

We can find which factor has a significant effect on the variations of system performance or quality characteristics of the product and which factor has an insignificant effect. The significant factors will stay in the statistical model and the insignificant factors will be removed from the model. The best or robust parameters setting of design factors will be selected based on the statistical model and optimization techniques. The parameter settings selected through this procedure can make the performance of the product insensitive to the undesired variations of the parameters of design factors, such as undesired but uncontrollable manufacturing variations due to mass production. For details, one can refer to $[10,11]$.Tolerance Design, at the expense of higher cost, is usually used to tighten the tolerances to reduce the variations in product's performances. In this step, designers balance quality and cost to meet or exceed the requirement of the design specification. By integrating environmental factors, we can design tolerances or allowances that can lead to less societal loss. The tolerance design is performed, based on quality loss function [12], economic effects of upgrading components and parts or materials. Traditionally, the design is aimed at minimizing the quality loss by selecting the best tolerances setting. References [13,14] give systematic studies on the details of the tolerance design.

\section{CONCURRENT ENGINEERING}

Concurrent Engineering: the traditional design of product, the preceding constraints and limitations are considered sequentially. In order to reduce the product development cycle time and cost and increase quality and productivity, concurrent (simultaneous) design of product and process has been introduced. The basic idea of concurrent engineering $(C E)$ is to shorten the time horizon in which the design and manufacturing constraints are introduced. CE refers to integration of product design and manufacturing processes. It integrates various activities within the broad scope of the product life cycle [15-18]. In CE the product design is viewed as a strategic task that has a major effect on the manufacturing activities. Design of product determines their quality and 70 to $80 \%$ of the final production cost [19] and 70 $\%$ of the life cycle cost of a product is determined at the conceptual design stage [20]. Product design in CE is viewed as a teamwork approach [21]. Consequently, integration requires that quantitative relationships among customer requirement, marketing, product design, materials, manufacturing process and equipment capabilities, and relatives be well understood. In this way for example changes in material requirements, product types, or market demand can be accommodated. Also, high quality is far more attainable via the integration of design and manufacturing [22]. 


\section{STEP (STANDARD FOR EXCHANGE OF PRODUCT DATA)}

The need for efficient and reliable communication of product information has been recognised since the 1980s. National standards for solving this problem are not adequate because product, production and marketing is a global issue. International accepted principle for communicating product definition data is the use of a single neutral file format. STEP is the latest standard that integrates capabilities of all relative previous standards in a single Standard for the External representation of Product definition data. Standard for the exchange of product (STEP) is the international standard (ISO) (ISO 10303) that is being developed as a result of international collaboration between organisations such as CAD*I (ESPRIT) project 322) and IGES|PDES Organizations in the USA, those who have been developing current formats, to produce a formal specification, testing and implementation aids, together with documented procedures, so all the objectives to the current formats are met. As an international standard it incorporates the experience that has been accumulated over the years from the national standards such as IGES,SET, and VDA.ISO is a collection of standards for the computer interpretable representation and exchange of product information. Its objective is to provide a mechanism that is capable for describing product data throughout the life of the product, independent from any particular computer system, ie. in a neutral format. The nature of this description makes it suitable not only for neutral file exchange, but also as a basis for implementing and sharing product databases and archiving, and for direct access to product data by application programs. The product data description is developed using a formal method to define all ideas and concepts uniquely and consistently. Therefore, ISO 10303 is a set of international standards for the computer sensible representation and exchange of product data. The language that is used to support this method is express (ISO 10303 part 11).A formal specification language such as EXPRESS, which is used to specify the representation of the product information, enables precision and consistency of representation and facilitates the development of implementations. The foundemental approach of ISO 10303 is that it separates the representation of product information from the implementation method (a specified technique for the exchange of product data of an application protocol (the representation of product information for one or more applications)). The approach used for the representation is to provide one product definition data which is common to many applications. These common representations can be tailored to the specific needs of the applications themselves. Integrated product development which is combination of Computer based concurrent engineering is the key element for reducing of lead time, cost and increasing quality, market share and benefit. In order to achieve these goal it is necessary to have open system so that harmonise data structures, information flows and standardised interfaces should be possible. Standardised interfaces lead us to the following benefits; 1 - Access to data produced and archive on computer equipment which is no longer in active use; 2- Communication between hardware and software from different vendors; and Agents, 3- Paperless exchange of information. The use of design standards and standard parts throughout the design of a product can substantially reduce production costs and make the company more competitive.

A CAD system for concurrent design must therefore encourage the use of design standards and standard components by making the relevant information readily available to designers in a manner which is obvious to them and which does not require the use of the kind of complex system commands that interrupt the creative design process. The following factors are very important in international standard. 1- Concepts (or reference models); 2- Formal data model specifications; 3- Protocol specification;and4- Information access specifications.

\section{EXPERT SYSTEM AND ITS COMPONENT}

Expert Systems are computer programs that are derived from Artificial Intelligence (Al). Expert system goal is to understand intelligence by building computer programs that exhibit intelligent behavior. It is concerned with the concepts and methods of symbolic inference, or reasoning, by a computer, and how the knowledge used to make those inferences will be represented inside the machine. The term intelligence covers many cognitive skills, including the ability to solve problems, learn, and understand language. But most progress to date in expert system has been made in the area of problem solving -- concepts and methods for building programs that reason about problems rather than calculate a solution. Expert systems that achieve expert-level competence in solving problems in task areas by bringing to bear a body of knowledge about specific tasks are called knowledge-based systems. Expert systems are programs whose knowledge base contains the knowledge used by human experts, in contrast to knowledge gathered from textbooks or non-experts. Expert systems and knowledge-based systems (KBS), are used synonymously. Taken together, the area of human intellectual endeavor to be captured in this expert system is called the design and manufacturing domain. Design and manufacturing is a domain of this expert system and refers to some goal-oriented, problem-solving activity. Design and manufacturing expert system refers to the area within which the task is being performed. Typical tasks are diagnosis, planning, scheduling, configuration and design.

\section{Knowledge engineer}

Building an expert system is known as knowledge engineering and its practitioners are called knowledge engineers. The knowledge engineer must make sure that the computer has all the knowledge needed to solve a problem. The knowledge engineer must choose one or more forms in which to represent the required knowledge as symbol patterns in the memory of the computer. Knowledge engineer should capture knowledge and must choose a knowledge representation and must also ensure that the computer can use the knowledge efficiently by selecting from a handful of reasoning methods. In the other hand a knowledge engineer interviews and observes a human expert or a group of experts and learns what the experts know, and how they reason with their knowledge. The engineer then translates the knowledge into a computerusable language, and designs an inference engine, a reasoning structure, that uses the knowledge appropriately. He also determines how to integrate the use of uncertain knowledge in the reasoning process, and what kinds of explanation would be useful to the end user. Next, the inference engine and facilities for representing knowledge and for explaining are programmed, and the domain knowledge is entered into the program piece by piece. It may be that the inference 
engine is not just right; the form of knowledge representation is awkward for the kind of knowledge needed for the task; and the expert might decide the pieces of knowledge are wrong. All these are discovered and modified as the expert system gradually gains competence. The discovery and cumulation of techniques of machine reasoning and knowledge representation is generally the work of artificial intelligence research. The discovery and cumulation of knowledge of a task domain is the province of domain experts. Domain knowledge consists of both formal, textbook knowledge, and experiential knowledge -- the expertise of the experts.

\section{Knowledge acquisition}

There are different methods for knowledge acquisition. The basic approach for knowledge engineering is interviews and observes a human expert or a group of experts and learns what the experts know, and how they reason with their knowledge. The knowledge engineer then translates the knowledge into a computer-usable language, and designs an inference engine, a reasoning structure, that uses the knowledge appropriately. Knowledge engineers also determine how to integrate the use of uncertain knowledge in the reasoning process, and what kinds of explanation would be useful to the end user.

\section{Inference engine and facilities}

The inference engine and facilities for representing knowledge and for explaining are programmed, and the domain knowledge is entered into the program piece by piece. It may be that the inference engine is not just right; the form of knowledge representation is awkward for the kind of knowledge needed for the task; and the expert might decide the pieces of knowledge are wrong. All these are discovered and modified as the expert system gradually gains competence. The discovery and cumulation of techniques of machine reasoning and knowledge representation is generally the work of artificial intelligence research. The discovery and cumulation of knowledge of a task domain is the province of domain experts. Domain knowledge consists of both formal, textbook knowledge, and experiential knowledge -- the expertise of the experts.

\section{Components of the expert system}

This expert system consists of four principal parts: 1) the knowledge base; 2) the reasoning, or inference, engine. 3) user interface, 4)text , slid, picture, video and audio files.

\section{Knowledge base}

The knowledge base of expert systems contains both factual and heuristic knowledge about design and manufacturing

\section{Factual Knowledge}

Factual knowledge is that knowledge of design and manufacturing that is widely shared, typically found in textbooks or journals, and commonly agreed upon by those knowledgeable in the design and manufacturing field.

\section{Heuristic Knowledge}

Heuristic knowledge is the less rigorous, more experiential, more judgmental knowledge of performance. Both type of knewlege is used in this expert system. It is the knowledge of good practice, good judgment in design and manufacturing. Heuristic knowledge is the knowledge that underlies the "art of good guessing."

\section{Knowledge representation}

Knowledge representation of design and manufacturing is a process in which knowledge can be formalized and organized. One approach which is widely used for representation is the production rule, or simply rule. Each rule consists of an IF part and a THEN part (also called a condition and an action). The IF part lists a set of conditions in design and manufacturing in some logical combination. The piece of knowledge represented by the production rule is relevant to the line of reasoning being developed if the IF part of the rule is satisfied; consequently, the THEN part of rules can be concluded, or its problem-solving action taken. This Expert system whose knowledge is represented in rule form is called rule-based systems.

\section{Frame representation}

Another widely used representation, called the frame, schema, unit, or list structure) is based upon a more passive view of knowledge. One can build roules by using frame. The Frame base approach is an assemblage of associated symbolic knowledge about an entity to be represented. Typically, a frame consists of a list of properties of the entity and associated values for those properties. Since every task domain consists of many entities that stand in various relations, the properties can also be used to specify relations, and the values of these properties are the names of other units that are linked according to the relations. One unit can also represent knowledge that is a "special case" of another unit, or some units can be "parts of" another unit. The problem-solving model, or paradigm, organizes and controls the steps taken to solve the problem in design and manufacturing. One common and powerful paradigm involves chaining of IF-THEN rules to form a line of reasoning.

\section{Forward Chaining}

If the chaining starts from a set of conditions and moves toward some conclusion, the method is called forward chaining.

\section{Backwards Chaining}

If the conclusion is known (for example, a goal to be achieved) but the path to that conclusion is not known, then reasoning backwards is called for, and the method is backward chaining. These problem-solving methods are built into 
program modules called inference engines or inference procedures that manipulate and use knowledge in the knowledge base to form a line of reasoning for design and manufacturing. The knowledge base an expert uses is what he learned at school, from colleagues, and from years of experience. Presumably the more experience he has, the larger his store of knowledge. Knowledge allows him to interpret the information in his databases to advantage in diagnosis, design, and analysis. Though an expert system consists primarily of a knowledge base and an inference engine, a couple of other features are worth mentioning: reasoning with uncertainty, and explanation of the line of reasoning.

\section{Reasoning with Uncertainty}

Design and manufacturing Knowledge is almost always incomplete and uncertain. To deal with uncertain knowledge, a rule may have associated with it a confidence factor or a weight. The set of methods for using uncertain knowledge in combination with uncertain data in the reasoning process is called reasoning with uncertainty. An important subclass of methods for reasoning with uncertainty is called "fuzzy logic," and the systems that use them are known as "fuzzy systems." Because an expert system uses uncertain or heuristic knowledge (as we humans do) its credibility is often in question (as is the case with humans). When an answer to a problem is questionable, we tend to want to know the rationale. If the rationale seems plausible, we tend to believe the answer. So it is with expert systems. Most expert systems have the ability to answer questions of the form: "Why is the answer X?" Explanations can be generated by tracing the line of reasoning used by the inference engine. The most important ingredient in any expert system is knowledge. The power of expert systems resides in the specific, high-quality knowledge they contain about task domains. Expert system researchers will continue to explore and add to the current repertoire of knowledge representation and reasoning methods. But in knowledge resides the power. Because of the importance of knowledge in expert systems and because the current knowledge acquisition method is slow and tedious, much of the future of expert systems depends on breaking the knowledge acquisition bottleneck and in codifying and representing a large knowledge infrastructure.

\section{Knowledge engineering}

Knowledge engineering is the art of designing and building expert systems, and knowledge engineers are its practitioners. Knowledge engineering is an applied part of the science of artificial intelligence which, in turn, is a part of computer science. Theoretically, then, a knowledge engineer is a computer scientist who knows how to design and implement programs that incorporate artificial intelligence techniques.

\section{Methods for building expert system}

Today there are two ways to build an expert system. They can be built from scratch, or built using a piece of development software known as a "tool" or a "shell."

\section{Built expert system from scratch}

The knowledge engineer, translates the knowledge acquired into a computer-usable language, and designs an inference engine, a reasoning structure, that uses the knowledge appropriately. He also determines how to integrate the use of uncertain knowledge in the reasoning process, and what kinds of explanation would be useful to the end user. Next, the inference engine and facilities for representing knowledge and for explaining are programmed, and the domain knowledge is entered into the program piece by piece. It may be that the inference engine is not just right; the form of knowledge representation is awkward for the kind of knowledge needed for the task; and the expert might decide the pieces of knowledge are wrong. All these are discovered and modified as the expert system gradually gains competence. The discovery and cumulation of techniques of machine reasoning and knowledge representation is generally the work of artificial intelligence research. The discovery and cumulation of knowledge of a task domain is the province of domain experts. Domain knowledge consists of both formal, textbook knowledge, and experiential knowledge -- the expertise of the experts.

Special programming languages In the late 1950s, special programming languages were invented that facilitate symbol manipulation. The most prominent is called LISP (LISt Processing). Because of its simple elegance and flexibility, most AI research programs are written in LISP, but commercial applications have moved away from LISP. In the early 1970s another Al programming language was invented in France. It is called PROLOG (PROgramming in LOGic). LISP has its roots in one area of mathematics. PROLOG in another (first-order predicate calculus). PROLOG consists of English-like statements which are facts (assertions), rules (of inference), and questions. Here is an inference rule: "If object-x is part-of object-y then a component-of object-y is object-x." Programs written in PROLOG have behavior similar to rule-based systems written in LISP. PROLOG, however, did not immediately become a language of choice for Al programmers. In the early 1980s it was given impetus with the announcement by the Japanese that they would use a logic programming language for the Fifth Generation Computing Systems (FGCS) Project. A variety of logic-based programming languages have since arisen, and the term prolog has become generic.

\section{using Tools, Shells, and Skeletons}

Compared to the wide variation in domain knowledge, only a small number of Al methods are known that are useful in expert systems. That is, currently there are only a handful of ways in which to represent knowledge, or to make inferences, or to generate explanations. Thus, systems can be built that contain these useful methods without any domain-specific knowledge. Such systems are known as skeletal systems, shells, or simply Al tools. Building expert systems by using shells offers significant advantages. A system can be built to perform a unique task by entering into a shell all the necessary knowledge about a task domain. The inference engine that applies the knowledge to the task at hand is built into the shell. If the program is not very complicated and if an expert has had some training in the use of a shell, the expert 
can enter the knowledge himself. Many commercial shells are available today, ranging in size from shells on PCs, to shells on workstations, to shells on large mainframe computers. They range in price from hundreds to tens of thousands of dollars, and range in complexity from simple, forward-chained, rule-based systems requiring two days of training to those so complex that only highly trained knowledge engineers can use them to advantage. They range from general-purpose shells to shells custom-tailored to a class of tasks, such as financial planning or real-time process control. Although shells simplify programming, in general they don't help with knowledge acquisition. Knowledge acquisition refers to the task of endowing expert systems with knowledge, a task currently performed by knowledge engineers.

\section{DESIGN OF EXPERT SYSTEM}

One of the tools for closing the gap between design and manufacturing is expert systems. An expert system which is generally, defined as an intelligent computer program that has capability to solve difficult real-life problems by the use of knowledge base and inference procedures. The goal of an expert system is the capability to conduct an intellectually demanding task in the way that a human expert would. The field of knowledge required to perform this task is called the domain of the expert system. Expert system utilizes a knowledge base containing facts, data, definitions, and assumptions. They also have the capacity for heuristic approach that is making good judgment on the basis of discovery and revelation, and making high probability guesses just as a human expert would [23]. The expert system is used in 'this approach to optimize design parameter including product cycle time and cost. An expert system for design and manufacturing for CNC machine center has been developed in a CE environment, the latest version of an expert system shell (NEXPERT), based on object-oriented techniques (OOT) is used. Figure 1 demonesrates how the system is worked in computer base concurrent engineering environment. A Hewlett Packard (HP) workstation was used in development of the expert systems. A geometric description of the design feature of the component is sent for optimization and manufacturability evaluation at the various stages of product development. Within the optimization and manufacturability procedure, the machining cycle time, cost, feed, efficiency, and other machining are estimated. The need for efficient manufacturing has to be balanced against the cost and time needed to achieve a product of the right quality. Feature based approach is used to obtained design specification. Design features are described in terms of its geometry, and the amount of material to be subsequently removed. The properties of work piece materials, tool materials, and machining parameters are stored in data-bases. The expert system can retrieve information from the data bases or working memory and advise the designer or manufacturing engineers on the suitable choice of material, tool, and machining conditions. The expert system also contains information needed for manufacturability evaluation and optimization, selection of alternative machining processes, knowledge of three dimensional design representations in terms of rules for good practice, machine and process capabilities, and constraints on features that can be manufactured by a particular process. For the present Expert system knowledge has been gathered from experiments. on machine center and experts. Machine cycle time and cost feed are also key factors, which depend on the type of material, tool and machining conditions. The choice of reasoning method, or a shell, is important, but it isn't as important as the accumulation of highquality knowledge. main component of CAD/CAM Expert system in computer based concurrent engineering is demonstrated in figure1.

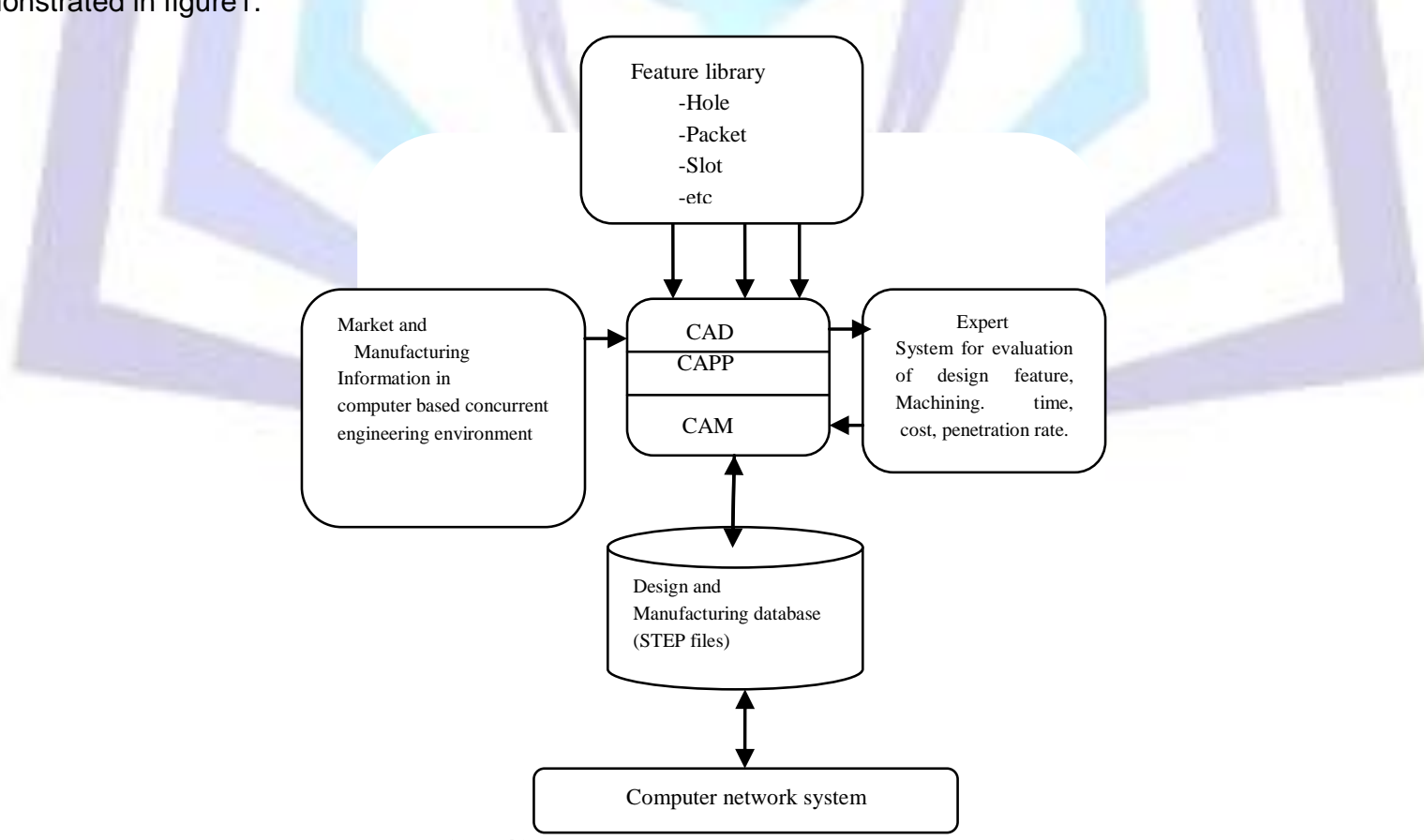

Fig1: main component of CAD/CAM Expert system in computer based concurrent engineering

\section{EXPERIMENTAL CNC MACHINING CENTER}

The expert system described above was compared with experimental CNC machinining center. In Figure 2 Overall view of Mazak machine center is demonstrated. 


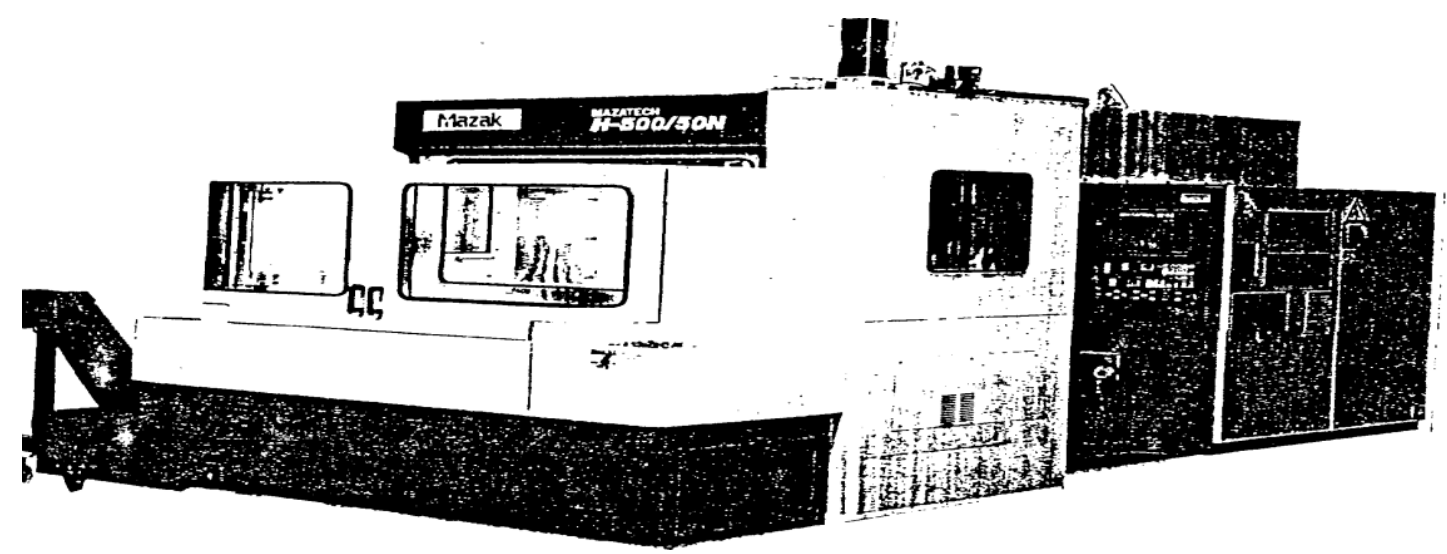

Fig 2: Overall view of Mazak machine center

The results are presented in table 1. The CNC machining center used in this experiment is Mazatech_CNC Machinining centre with the following characteristics:

Mazatech Machine Specifications

Machine name: Mazatech $\mathrm{H}$

Machine limitation

- spindle motor AC $15 \mathrm{KW}$

- speed 35-6000 rpm

- torque $60.8 \mathrm{kgf.m}$

- power output 240-6000 rpm

Machining dimension limitation:

- $x$ access $720 \mathrm{~mm}$

- y access $650 \mathrm{~mm}$

-z access $650 \mathrm{~mm}$

\section{Tool limitations:}

- maximum len. $450 \mathrm{~mm}$

-max. diameter $130 \mathrm{~mm}$

- maximum weight $27 \mathrm{~kg}$

- toolchange time $2.5 \mathrm{sec}$

\section{Table limitation}

- size 500*500 mm

- rotation speed $11 \mathrm{rpm}$

-Table accuracy $(\mu \mathrm{m})$

- table index incrim. $1^{\circ}$

- magazine tool number. 40

- pallet size 500*500

- max. workpiece 500*500

- max workpiece weight $1000 \mathrm{~kg}$ $\underline{\text { Machine accuracv limitation: }}$

- repeatability $\pm 15 \mu \mathrm{m}$

- pallet change $12 \mathrm{sec}$

- pallet change accuracy $\pm 5 \mu \mathrm{m}$

- maximum tool weight $27 \mathrm{~kg}$

- cutting feed rate $8000 \mathrm{mmpm}$

- roundness $\pm 5 \mu \mathrm{m}$

- perpendicularity $\pm 5 \mu \mathrm{m}$

In figure 3 flow chart of the expert system for CAD/CAM evaluation and optimization is demonstrated. A designer uses proengineers software and uses feature base library and design a part. Design data base on international standard STEP store in design data base. 


\section{ISSN 2277-3061}

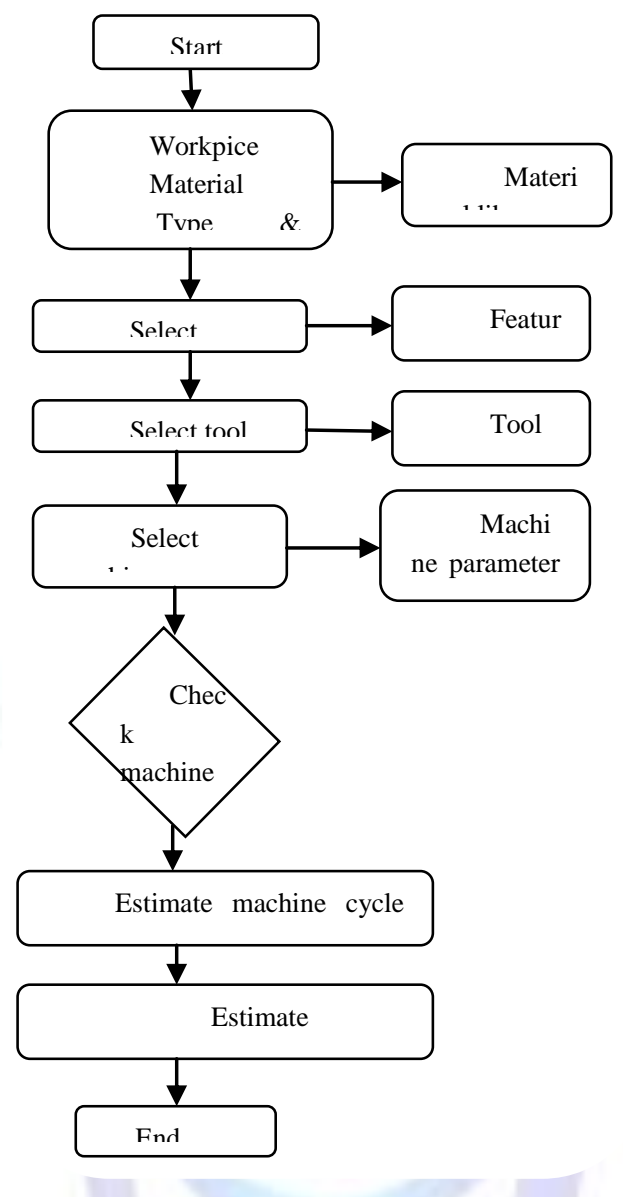

Fig 3: Flow chart of the expert system for design evaluation and optimization

All suppliers can used the latest design data through computer network system. The power of an expert system lies in its store of knowledge about the task domain. The more knowledge a system is given, the more competent it becomes. In figure 4. A Typical rules for expert system is shown. In figure 5. Expert System Approach for CAD/CAM integration and based on international Standard (STEP) and computer based concurrent engineering environment is demonstrated. In practical, estimation of machining time and cost, penetration rate and all other parameters are difficult to obtain. In contrast the expert system can provide this estimation usually in less than 20 seconds.

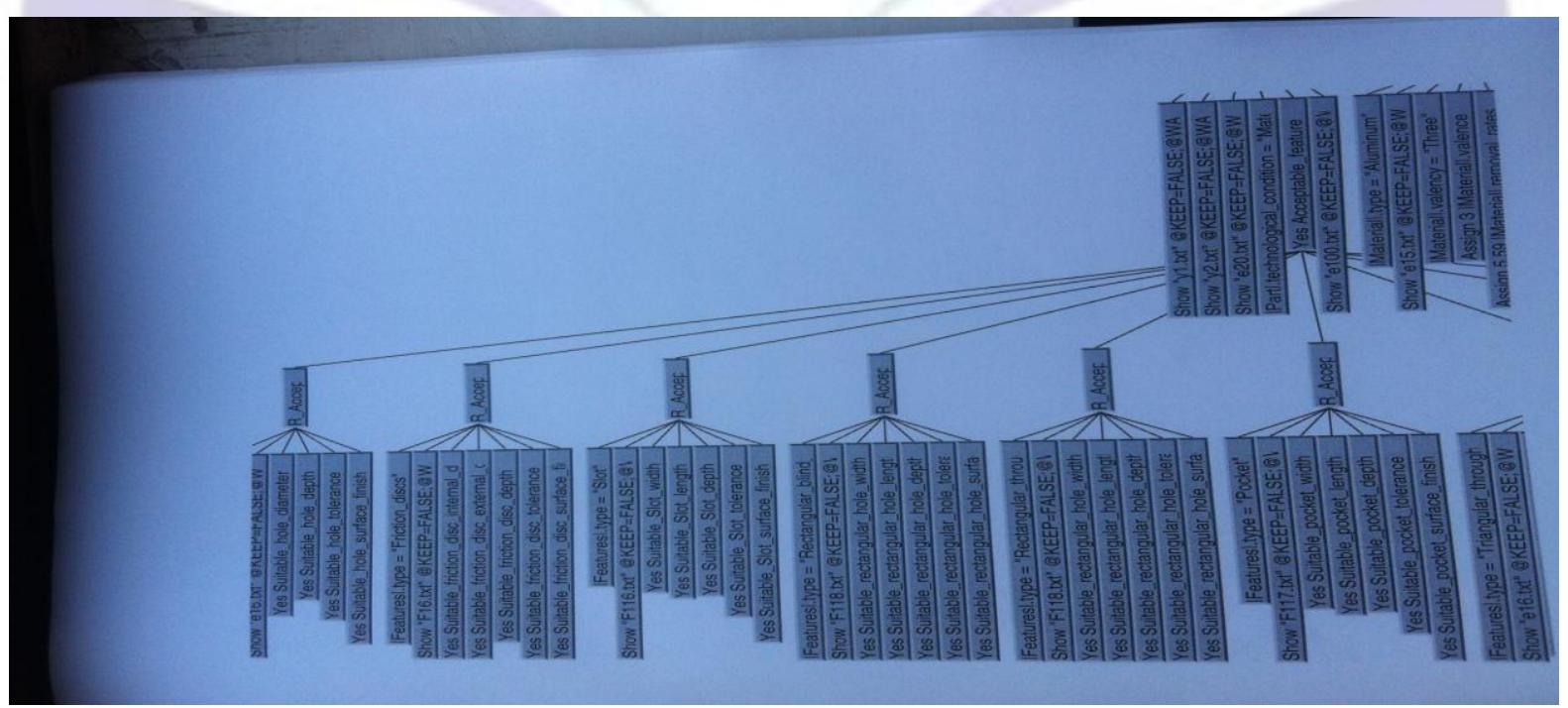

Fig 4:Typical rules in above expert system 


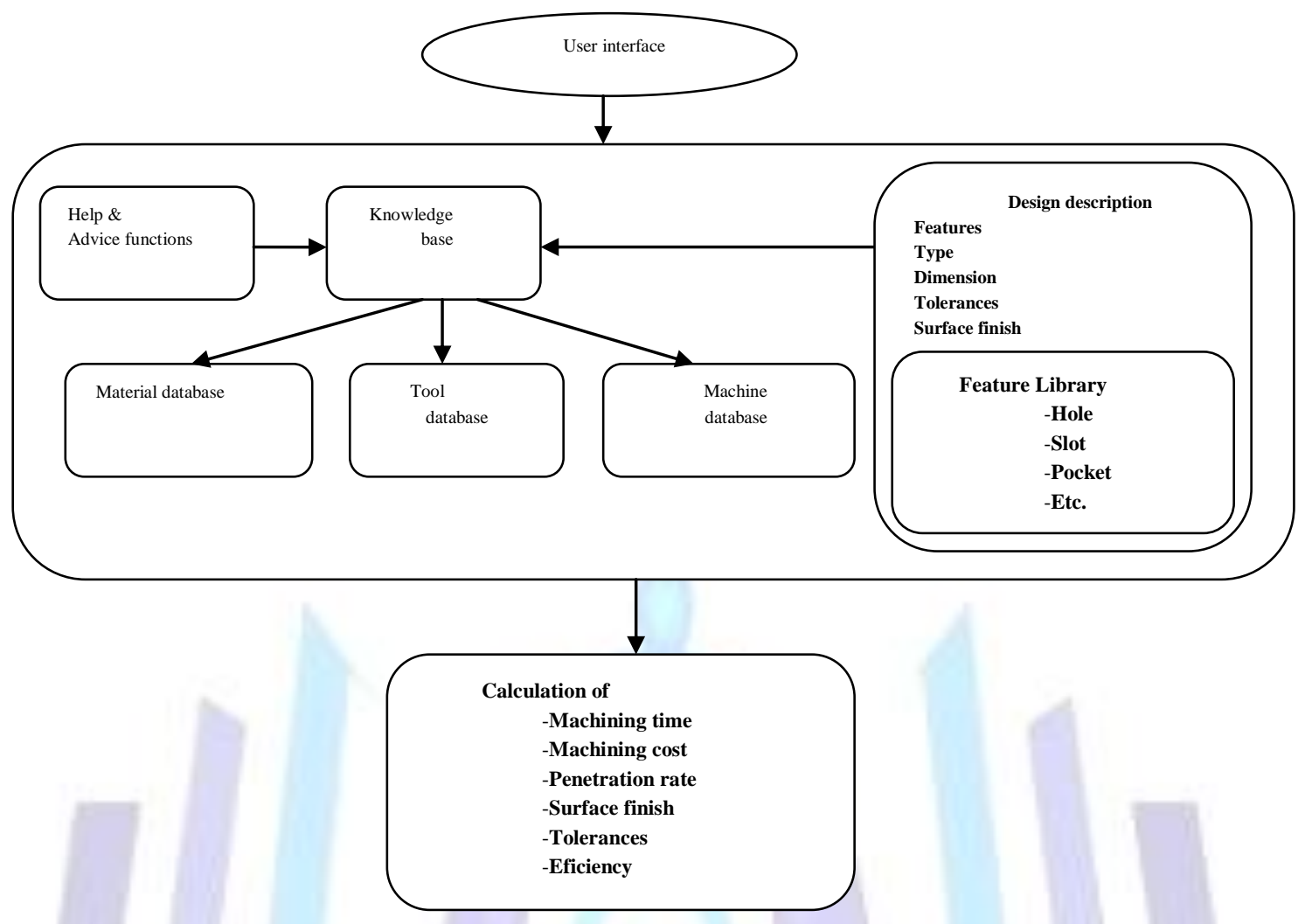

Fig 5: Expert System Approach for CAD/CAM integration and evaluation base on international Standard STEP and computer based concurrent engineering environment

Table 1: Experimental CNC and Expert system results:

\begin{tabular}{|c|c|c|c|c|c|c|c|c|}
\hline & Feature & & Expe & rt System & & \multicolumn{3}{|c|}{ Experimental } \\
\hline $\begin{array}{l}\text { Machining } \\
\text { Type }\end{array}$ & $\begin{array}{l}\text { Machining } \\
\text { Specification }\end{array}$ & Procedure & $\begin{array}{l}\text { Feed rate } \\
\text { cycle time }\end{array}$ & $\begin{array}{l}\text { Machining } \\
\operatorname{cost}(\$)\end{array}$ & $\begin{array}{l}\text { Machining } \\
\mathrm{mm} / \mathrm{min}\end{array}$ & $\begin{array}{l}\text { Feed rate } \\
\text { cycle time }\end{array}$ & $\begin{array}{c}\text { Machining } \\
\operatorname{cost}(\$)\end{array}$ & $\begin{array}{l}\text { Machining } \\
\mathrm{mm} / \mathrm{min}\end{array}$ \\
\hline Hole1 & $10 \mathrm{~mm}$ dia & Drilling & 0.56 & 0.142 & 17.86 & 0.59 & 0.15 & 17.14 \\
\hline Hole2 & $10 \mathrm{~mm}$ dia & Drilling +reaming & 1.0 & 0.25 & 10.0 & 1.1 & 0.28 & 9.1 \\
\hline Hole3 & $10 \mathrm{~mm}$ dia & Drilling+boring & 1.23 & 0.31 & 8.13 & 1.33 & 0.34 & 7.5 \\
\hline Slot1 & $8 * 8 * 50 \mathrm{~mm}$ & Slot drilling & 2.29 & 0.58 & 3.49 & 2.79 & 0.70 & 2.86 \\
\hline Slot2 & $8^{\star} 8 * 50 \mathrm{~mm}$ & End milling & 2.51 & 0.64 & 3.19 & 2.92 & 0.75 & 2.74 \\
\hline Slot3 & $8 * 8 * 50 \mathrm{~mm}$ & Slot drilling+finishing & 4.57 & 1.17 & 1.75 & 4.84 & 1.23 & 1.65 \\
\hline Slot4 & $8^{\star} 8^{\star} 50 \mathrm{~mm}$ & End milling + finishing & 5.03 & 1.29 & 1.59 & 5.40 & 1,38 & 1.48 \\
\hline Pocket1 & $30 * 30 * 10 \mathrm{~mm}$ & Drilling+Slot drilling & 6.07 & 1.54 & 1.65 & 6.20 & 1.57 & 1.61 \\
\hline Pocket2 & $30 * 30 * 10 \mathrm{~mm}$ & Drilling+End milling & 6.60 & 1.68 & 1.52 & 7.30 & 1.60 & 1.59 \\
\hline Pocket3 & $30 * 30 * 10 \mathrm{~mm}$ & Drilling+slot D+finish & 7.82 & 2.00 & 1.28 & 8.53 & 1.92 & 1.33 \\
\hline Pocket4 & $30 * 30 * 10 \mathrm{~mm}$ & Drill+End mil+finish & 8.52 & 2.18 & 1.17 & 9.0 & 2.04 & 1.25 \\
\hline
\end{tabular}

\section{CONCLUSION}

An expert system for improving design and manufacturing process for based on international standard (STEP) and computer based concurrent engineering environment is developed. The system is linked with design database and also manufacturing data bases such as tool, work piece materials, and CNC machine center parameters data bases. For each design feature the system then automatically estimates all parameters such as machining cycle time, cost, total machining time and cost, penetration rate and other parameters demonstrated above. The system gives some advice to product 
designer and manufacturing engineers for improving design and manufacturing. It can be used as teaching software for training people who do not know how to work with machine center. The result of table 1 shows that the expert system estimates correctly machining cycle time and cost and penetration rate. In practical, estimation of machining time and cost, feeds and all other parameters are difficult to obtain. In contrast the expert system can provide this estimation usually in less than 20 seconds.

\section{REFERENCES}

[1] Kackar, R. N., "Off-line Quality Control, Parameter Design, and the Taguchi Method," Journal of Quality Technology, Vol.17, No. 4, 1985.

[2] Taguchi, G., Introduction to Quality Engineering, Unipub/Kraus International Publications, White Plains, NY and American Supplier Institute Inc., Dearborn, MI, 1986.

[3] Taguchi, G., "Quality engineering (Taguchi Methods) for the Development of Electronic Circuit Technology," IEEE Transactions on Reliability, Vol. 44, No. 2, 1995.

[4] Bullington, R. G. and Lovin, S., "Improvement of an Industrial Thermostat Using Designed Experiments," Journal of Quality Technology, Vol. 25, No. 4, 1993.

[5] Coleman, D. and Montgomery, D., "A Systematic Approach to Planning for a Designed Industrial Experiment," (with Discussion), Technometrics, Vol. 35, No.I, 1993.

[6] Chen, G., "Environmentally-Conscious Product Design by Material Reduction for Minimizing Societal Loss," Journal of Engineering Valuation and Cost Analysis, Vol. 1, No. 4, 1997.

[7] Chen, G., "Integrating Environmental Factors into Robust Design to Minimize Societal Loss", the Proceedings of the 4' International Conference on Manufacturing Technology in Hong Kong, Hong Kong, Nov. 30 - Dec. 3, 1997.

[8] Chen, G. and Kapur, Ź. Ń., "A Two-step Robust Design Procedure of Linear Dynamic Systems for Reducing Performance Variations," International Journal of Reliability, Quality and Safety Engineering, Vol. 4, No. 2, 1997.

[9] Chen, G. "Environmentally Conscious Robust Design and Manufacturing for Sustainable Development," a Chapter in Massie Book Special Elements of Environmental Engineering, 1996

[10] Chen, G. and Kapur, K. C., "Tolerance Design by Break-even Analysis for Reducing Variation and Cost," International Journal of Reliability, Quality and Safety Engineering, Vol. 1, No. 4,1994.

[11] Khattree, R., "Robust Parameter Design: a Response Surface Approach," Journal of Quality Technology, Vol. 28, No. 2, 1996.

[12] Chen, G. and Kapur, K. C., "Quality evaluation system using loss function". Proceedings of 1989 International Industrial Engineering Conference, Toronto, Canada, May 1989.

[13] Kapur, K. C. and Cho, Ā., "Economic Design of the Specification Region for Multiple Quality Characteristics," HE Transactions, Vol. 28, No. 3, 1996.

[14] Chen, G., "Tolerance Design Based on Variation Transfer Function," Proceedings of the 3rd LASTED, International Conference on Reliability, Quality Control and Risk Assessment, Washington, DC, Oct 3-5, 1994.

[15] Nevins, J. L., and Whitney, D. E. (1989). Concurrent Design of Products and Processes. New York: Mc Graw-Hill, 1989

[16] Vasilash, G. S.,1987, Simultaneous engineering, Management's new competitiveness tool product., July 1987, 41

[17] Sadegh Amalnik Morteza \& Alitavoli, A. 1994. A Generic IDEF0 Model of an Integrated Product Development in CIM environment based on Concurrent Engineering. in: G. Rzevski, R. A. Adey, D. W. Russell (Eds), Application of Artificial Intelligence in Engineering 9, Computational Mechanics Publications, pp. 455

[18] Sadegh Amalnik, Morteza ,1994, Integrated Product Development at Design and Manufacturing, Company, National and International level Based on Computer Based System and Concurrent Engineering. Proc. $4^{\text {th }}$ Int. Conf. On Factory 2000, IEE, University of York, Oct. 1994, pp. 349-356.

[19] O'Grady, P., Ramers, D., and Bolsen, J. Artificial intelligence constraint nets applied to design for economic manufacture. Computer Integrated Manufacturing, 1 (4), 1988

[20] Sadegh Amalnik, Morteza,1996,. An intelligent concurrent advisory and manufacturability evaluation system for conventional and unconventional processes for improved product design. Paisly University, Paisly, Scotland

[21] Whitney, D. E.(1988). Manufacturing by design. Harvard Business Review, August, pp. 87-88

[22] Kalpakjian, S., Schmid S. R.(2001). Manufacturing Engineering Technology. Prentice Hall

[23] Sadegh Amalnik Morteza and. McGeough, J.A.,1996, Intelligent Concurrent Manufacturability Evaluation of Design for Electrochemical Machining. Journal of Material Proc. Technology, 1996 


\section{Author' biography with photo}

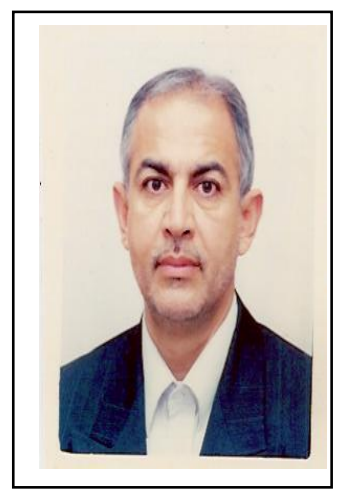

DR. Morteza Sadegh amalnik has been teaching and conducting research in design and manufacturing processes at University of Tabriz and University of Qom science 1996. After graduating from New York State University in USA in 1978, and after getting his PH.D from university of Paisly in United Kingdom. He works as an assistance professor in University of Tabriz and University of Qom and published more than 120 papers in ISI and International Journals and conferences. He is currently director of environment research organization with 10 research groups in various areas and assistance professor of Mechanical Engineering Department of University of Qom.

Doctor M.K. Moayyedi, is Assist. Prof. and currently director of education \& research in faculity of engineering. He is also Lecturer and Researcher in mechanical engineering department of Qom University

Doctor Mostafa Mirzaei is is Assist. Prof. of mechanical engineering in university of Qom University. 